Research Paper

\title{
Canonicity Effect on Sentence Processing of Persian-speaking Broca's Patients
}

\author{
Omid Azad $^{1 *}$
}

1. Department of Linguistics, Faculty of Humanities, University of Gonabad, Gonabad, Iran

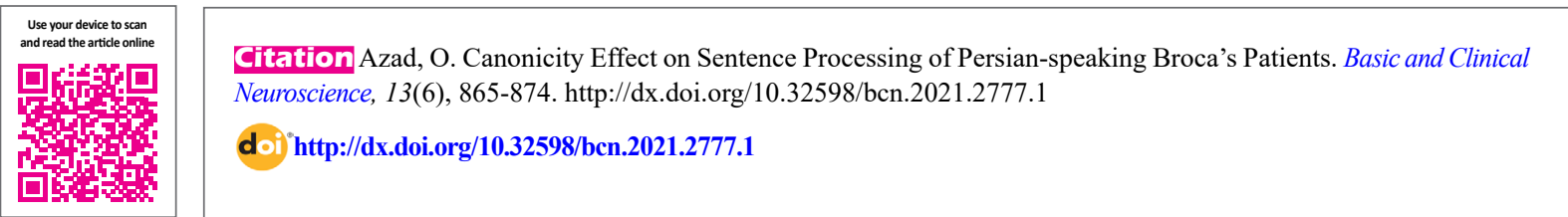

Article info:

Received: 27 Jul 2020

First Revision: 06 Nov 2021

Accepted: 21 Nov 2021

Available Online: 01 Nov 2022

Keywords:

Heuristics, Mapping hypothesis, Broca area, Object experience

\begin{abstract}
$\underline{\text { AB S T RAC T }}$
Introduction: Fundamental notions of mapping hypothesis and canonicity were scrutinized in Persian-speaking aphasics.

Methods: To this end, the performance of four age-, education-, and gender matched Persian-speaking Broca's patients and eight matched healthy controls in diverse complex structures were compared via the conduction of two tasks of syntactic comprehension and grammaticality judgment.

Results: The tested structures included subject agentive, agentive passive, object experience, subject experience, subject cleft, and object cleft constructions. Our results, while corroborating the predictions of the mapping hypothesis, showed that in structures, in which linguistic elements were substituted and dislocated out of their canonical syntactic positions, namely, agentive passive, subject experiencer, object experiencer, and object cleft constructions, Broca's problems escalated. In contrast, in those structures whose constituent concatenations were aligned with canonical syntactic structures, namely subject agentive, and cleft structures, patients had above the chance performance. Ultimately, the theoretical and clinical implications of the study were discussed.

Conclusion: The number of predicates in a sentence, predicate types (psychological and agentive), as well as semantic heuristics and canonicity all by all could be regarded as the major culprits for aphasics' poor performance.
\end{abstract}

\footnotetext{
* Corresponding Author:

Omid Azad, Assistant Professor

Address: Department of Linguistics, Faculty of Humanities, University of Gonabad, Gonabad, Iran.

Tel: +98 (911) 3203468

E-mail: oazad62@yahoo.com
} 


\section{Highlights}

- Broca's patients performed well in subject agentive and cleft structures.

- Broca's aphasics performed poorly in non-canonical structures like object experiencer, and cleft constructions.

- There was a main effect of task type in the performance of the patients.

- Canonicity plays a predominant role in the comprehension of aphasics.

\section{Plain Language Summary}

Brain damaged patients or Broca's aphasics have lots of challenges in the comprehension of syntactically complex structures. To account for the source of their challenge, scholars have recommended there famous theories including constraint satisfaction model, trace deletion model, and mapping hypothesis. The last aforementioned hypothesis simply asserts that typical word order arrangement accelerates comprehension. On the other hand, when words are dislocated from their original positions in a sentence, aphasics would perform more poorly. We testified the predictions of the mapping hypothesis in Persian language. Consequently, for example, it was predicted that in those sentences in which the object is placed at the beginning of the sentence, Broca's patients should have had more challenges, because in Persian language, the object of the sentence is usually used after the verb in the default situation. The results of our research in the four Persian-speaking Broca's aphasics corroborated this theory as it demonstrated that patients performed poorly in atypical structures while they performed well in canonical constructions. Considering the significance of "sentence" as the major unit of information exchange for participants in a conversation, clinicians, speech therapists, as well as care givers could concentrate more on the use of simple canonical sentences to facilitate the comprehension of aphasics.

\section{Introduction}

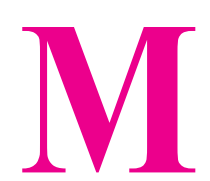

any studies have attempted to scrutinize sentential parsing in Broca's patients. Despite these abundant reviews of literature, there has still been some controversy regarding both the nature and extent of the deficit. To explain this type of controversy, some important theoretical accounts have emerged. Some interactive views of agrammatism proposed a constraint-satisfaction model of sentence processing expressing that once a required syntactic, semantic, or morpho-syntactic condition is met, the person would commence automatically comprehending the sentence (Frazier, 1995; Grodzinsky \& Finkel, 1998; Omazic, 2008; Seidenberg \& MacDonald, 2001). For example, the trade-off hypothesis proposes that in some syntactic structures, the parser does not need to analyze the whole sentence from the first linguistic element to the last. For her, it is sufficient as long as the processing needs are in question, which could allow her to make an accurate or acceptable judgment. As a result, holding a very general account of the nature of the processing in Broca's patients, they assign their deficit to the performance (Evans, Hula \& Starns, 2019; Frazier \& Friederici, 1991;
Ferrill et al., 2012; Haarmann, 1993; Haarmann \& Kolk, 1991; Kolk \& Van Grunsven., 1985).

The second theoretical account unlike other views, the trace deletion hypothesis, which has a very narrow and restrictive explanation of the nature of the grammatical deficit in Broca's aphasia, attributing the nature of the deficit to the malfunction of the grammatical module of the language and adopting some important theoretical notions from grammar and transformational theory of Noam Chomsky and more specifically his government and binding's (GB) theory (Chomsky, 1982, 1993). Grodzinsky and his proponents have attempted to attribute Broca's aphasics' inappropriate performance to their incapability of co-indexing traces and their original positions in the sentence holding the longer the chain and the sentence comprehension becomes more problematic. They emphasize that these lexical nodes co-indexed with their antecedents are either governed or bound (Beretta \& Munn, 1998; Grodzinsky, 1983, 1995, 2000; Grodzinsky, et al., 2000; Hickok., et al., 1993).

However, the mapping hypothesis unlike the two former theories has proposed that neither pure competence nor a sheer performance model of syntactic processing could plausibly justify Broca's patients' behaviors in dif- 
ferent tasks. That is, this model analyzes an individual's parsing at two stages. At the first syntactic level, there seems to be no significant deficit in aphasics' performance. However, in the second stage, subjects' poor performance would evince while trying to assign semantic roles to the syntactic positions in the sentence. Henceforth, followers of this theory have claimed that their subjects would not have any problems in tasks entailing grammatical judgments of the sentences due to the involvement of less cognitive load. Yet, in tasks, in which particular mapping is required for the plausible interpretation of the sentence, namely, sentence-to-picture matching task, their problems would emerge (ChoReyes \& Thompson, 2012; Dragoy \& Bastiaanse, 2010; Garraffa \& Grillo, 2008; Linebarger, 1995; O’Grady \& Lee, 2005; Piñango, 2000; Schwartz, et al., 1995; Schwartz., et al., 1985).

This research, being the first in the Persian context, tried to investigate the performance of Persian-speaking Broca patients within the framework of the mapping hypothesis. Our motives for conducting this research are multifold:

First, having considered the existing controversy in the literature regarding the nature of deficit, this study attempted to analyze Broca's performance on sentence parsing within the framework of the mapping hypothesis and in doing so, it aimed at testifying the validity of the predictions of the aforementioned model.

Second, unlike most former studies (Byng, 1988; Caplan et al., 2007; Meyer \& Thompson, 2012; Wassenaar \& Hagoort, 2007), adopting some methodological changes, this study combined two different grammatical judgment and sentence-to-picture matching tasks to increase the validity of the research and testify more efficiently the predictions of mapping hypothesis given its proposed double stage syntactic semantic model.

Third, it is noteworthy to mention that as of now although there have been only a few studies in the Persian context analyzing the performance of Broca's aphasics in sentence comprehension (Mehri, et al., 2016; Nilipour, 2000; Raghibdoust, 1999), they have neither attempted to utilize mapping hypothesis for the justification of subjects' performance nor did they combine diverse tasks for the explanation of their subjects' comprehension (Salehnejad \& Shekaramiz, 2016; Shiani et al., 2019) casting doubt on the validity of their research. Given these considerations, the necessity of conducting this research in a Persian setting seems compulsory and essential to depict a more realistic picture of the nature of grammatical deficits in these patients.

Fourth, this study also tried to investigate the probable impact of language typology via testifying subjects' performance on syntactic structures of Persian, which are mainly different from those of European languages. That is, in Persian as a so-called subject-object-verb (SOV) language, the dependent constituent precedes the verb in contrast with languages like English, in which the reverse concatenation pattern is the case. Moreover, unlike English and most European languages, bearing fixed syntactic structures, Persian has a rather floating structure meaning under certain circumstances for pragmatic and discoursal implications, the aforementioned SOV canonical order might change and another alternative category arrangement might be employed by the speakers (Karimi, 2003, 2008). It could be predicted that variations in syntactic arrangements of the linguistic elements might unconsciously affect Broca's patients' performance even in tasks, in which canonical syntactic structures of Persian have been utilized for the purpose of analyzing aphasics' comprehension. The significance of this typological difference would become more prominent, more specifically, in the mapping hypothesis as it is more vividly in this theory that the specific arrangement of linguistic elements would play a crucial role in subjects' interpretation and its disruption would culminate in misinterpretation of the sentence.

Ultimately, regarding the scope of Broca's aphasics in Iran, suffering comprehension problems, which would distort their interaction with healthy subjects, this research, having scrutinized the extent and nature of grammatical deficit in patients, attempted to provide some linguistic clues for the speech therapists or neuropsychologists whereby they could propose more effective styles of communication for the caregivers or patients' relatives whereby they could more efficiently negotiate and interact with their patients and thereafter via designing a much more satisfactory style of living to boost their life expectancy.

\section{Materials and Methods}

\section{Subjects}

Having analyzed the neuropsychological profile of each of the patients and reviewed their medical records as exhibited by $\mathrm{CT}$ scan, Electroencephalogram (EEG), and other neuropsychological tests, four age-, education-, and age-matched aphasics and eight healthy individuals as our control group were recruit- 
ed. Also, their auditory, tactile, and visual fields were reported to be normal. None of them was ambidextrous and they were neither left-handed nor had family background exhibited possessing these properties. Noteworthy to say, written consent proving patients' satisfaction to participate in the tasks was taken. In Table 1, the lesion descriptions of each patient are presented. Concerning our selected sample, it should be asserted that they were all male having an age range of 51 to 64 years. Moreover, for their educational background, they had achieved at least a diploma.

Our diagnostic tool for assessing aphasia type was Boston Diagnostic Aphasia Examination (Goodglass and Caplan, 1972). Having translated and confirmed the test in Persian testifying its reliability and validity, we utilized it to screen our subjects' aphasia type. Furthermore, the review of the neuroradiology of patients corroborates our evaluation demonstrating our classification was in line with the classical Broca's type. The common characteristics of all patients were their effortful, telegraphic, and ungrammatical as well as their rather intact syntactic comprehension capabilities. This observation is not surprising given the fact that it has been scientifically proven that agrammatism is typically a syndrome of aphasia patients (Tesok \& Code, 2008).

Noteworthy to mention, though the lesion site description of each Broca patient has been presented, as Ingram asserted no designated and compartmentalized lesion site could culminate in agrammatism and it has been scientifically attested that interaction of cell assemblies is involved in this syndrome. Thus, the properties of agrammatism could well be defined via psycholinguistic tests rather than clinical observations (Ingram, 2007). Taking this important scientific consideration, we could understand more of the nature of agrammatism in Broca's aphasia patients by conducting a syntactic comprehension test, and why administering such a test could be fruitful.

\section{Procedure}

\section{Grammaticality Judgment task}

Totally, a hundred and twenty sentences of six group types were presented to the subjects. The first type included those sentences, in which the subject is regarded as the agent of the sentence (agentive type). For example, "Ali sib ra xord" is rendered in English as "Ali ate the apple". An important typological property worthy of consideration here is that Persian belongs to OV or headfinal group of languages- unlike English categorized as a VO or head initial group of languages- meaning it is the object, which precedes the verb in the canonical syntactic structure. The second group of sentences included agentive passive structures, in which the semantic role of the patient or theme or logical object that occupies the initial subject position of the sentence and the original subject is moved to the preverbal position of the sentence "ketab (tavassote mard) neve fte fod" rendered in English as "the book was written (by the man)".

In Persian, unlike English, agentive by-phrase occurs in the pre-verbal position, which could also be optionally deleted. The third group of sentences includes subject cleft constructions, in which the main verb follows the subject observing the canonical syntactic structure. For example, "Pin doxtar bud ke sib ra xord" is rendered in English as "It was this girl who ate the apple". The fourth group includes object cleft structure, in which unlike subject cleft, canonical linear syntactic structure is disrupted in a way that it is the object rather than the subject, which occupies the initial position of the sentence. For example, "Pin pesar bud ke doxtar donbalesh kard" is rendered in English as "It was the boy who the girl followed". The fifth group includes the subject experiencer type. Possessing psychological predicates, these sentences encompass those structures, which unlike the default syntactic structure, in which it is common that the subject occupies the semantic role of agent, deviate from the norm in the way that the entity psychologically affected by a specific stimulus would occupy the subject position of the sentence. For example, "Kudak az gorbe tarsid" is rendered in English as "The baby feared the cat". Finally, the last group includes object experiencer verbs. These structures, compared to the subject experience verbs, deviate even more from the canonical linear heuristics in the way that it is the less default and remote object in the syntactic structure, which substitutes for the subject. For example, "Mard zan ra tarsand" is rendered in English as "The man frightened the woman".

\section{Syntactic comprehension task}

For the purpose of evaluating our subjects' performance on the syntactic comprehension test and their capability to assign thematic roles to the noun phrases, a figurine act-out task was administered, based on which all subjects were expected to act out and sort a set of randomized toy figurines having heard a group of diverse sentences. Due to our patient's requests, the testing sessions were conducted at their homes. The subjects were told that they should manipulate the toy figurines in a way that the action or the state expressed by the verb could be easily detected. 
Table 1. Lesion site descriptions of patients

\begin{tabular}{cll}
\hline Name & Diagnosis (BDAE and Clinical Consensus) & \multicolumn{1}{c}{ Lesion Site Information } \\
\hline MS & Broca's & $\begin{array}{l}\text { MS is a male suffering a stroke in 1992. An MRI taken that year dem- } \\
\text { onstrated a diffuse lesion site including the posterior frontal lobe and } \\
\text { perisylvian area }\end{array}$ \\
BR & Broca & $\begin{array}{l}\text { BR is a male suffering a stroke due to a cardiovascular accident in } 1995 . \\
\text { The lesion site involved was the inferior anterior parietal lobe }\end{array}$ \\
Broca & $\begin{array}{l}\text { SP is a male with a cardiovascular accident in 1999. A CT scan taken } \\
\text { that year demonstrated lesions in the Perisylvian area. }\end{array}$ \\
GL & Broca & $\begin{array}{l}\text { GL is a male suffering an accident in 2001. The study of CT taken that } \\
\text { year showed the involvement of lesion sites including the left temporal } \\
\text { lobe as well as the perisylvian area. }\end{array}$ \\
\hline
\end{tabular}

NEUR SCIENCE

For the purpose of the subjects' familiarity with the task, four practice trials were utilized initially. However, in case the subject demanded the experimenter to repeat the sentence, it was uttered for the second time. There was no particular time limit for the task until the experimenter was confident that the patient performed the task completely having understood the procedure. Noteworthy to mention is that all stimuli were presented to the patients in the same randomized order. Furthermore, following the procedure employed by Linebarger et al. (1983), and also for the purpose of minimizing the impact of prosodic and intonation properties on patients' performance, all stimuli were uttered by the same experimenter observing approximately similar intonation patterns.

\section{Results}

\section{Syntactic comprehension task}

For the purpose of detecting a possible pattern in subjects' performance as well as investigating whether canonicity impact could be observed in their linguistic behaviors, each individual's performance in diverse syntactic structures was reported.

In this respect, one-way repeated measures ANOVA for the six group types of sentences culminated in the main effect of sentence type $\left(\mathrm{F}_{(6,38)}=33.95, \mathrm{P}<0.0001\right)$. The performance of our first subject on subject agent and subject cleft structures was $95 \%$ and $91 \%$ correct responses, respectively, significantly above the chance (subject agent: $\mathrm{t}_{(20)}=3.91, \mathrm{P}=0.0005$; subject cleft: $\left.\mathrm{t}_{(20)}=3.48, \mathrm{P}=0.001\right)$. As for agentive passive and object cleft constructions, his performance was at chance with $50 \%$ correct responses $\left(\mathrm{t}_{(20)}=0.88, \mathrm{P}=0.31\right)$ and $48 \%$ correct responses $\left(\mathrm{t}_{(20)}=0.85, \mathrm{P}=0.33\right)$, respectively. Yet, concerning both subject experience constructions (thirty percent correct responses, $\left.\mathrm{t}_{(19)}=-3.31, \mathrm{P}=0.817\right)$ and object experiencer ones $\left(25 \%\right.$ correct responses, $\left.\mathrm{t}_{(19)}=-4.33, \mathrm{P}=0.818\right)$, his performance was significantly below the chance.

Subject two (BR) performed above the chance at $86 \%$ of the subject agentive constructions $\left(\mathrm{t}_{(20)}=2.92\right.$, $\mathrm{P}=0.005)$. Concerning his performance at subject cleft ( $86 \%$ correct responses), a similar observation was made $\left(\mathrm{t}_{(20)}=2.76, \mathrm{P}=0.005\right)$. As for agentive passive, he had a chance performance with $60 \%$ correct responses $\left(\mathrm{t}_{(20)}=0.87, \mathrm{P}=0.53\right)$. However, regarding object cleft constructions, he had below the chance performance with $47 \%$ correct responses $\left(\mathrm{t}_{(20)}=1.43, \mathrm{P}=0.818\right)$. Ultimately, concerning the psychological subject and object experiencer types, he had significantly below the chance performance with $29 \%$ correct responses in the former $\left(\mathrm{t}_{(20)}=-3.32, \mathrm{P}=0.819\right)$ and $24 \%$ correct responses in the latter $\left(\mathrm{t}_{(20)}=-4.21, \mathrm{P}=0.819\right)$. Subject three (SP) performed above the chance in both subject agentive $\left(85 \%\right.$ correct responses, $\left.\mathrm{t}_{(20)}=2.55, \mathrm{P}=0.014\right)$ and subject cleft constructions (80\% correct responses, $\mathrm{t}_{(20)}=2.14$, $\mathrm{P}=0.022$ ). Concerning agentive passives with $52 \%$ correct responses $\left(\mathrm{t}_{(20)}=0.97, \mathrm{P}=0.33\right)$ and object cleft constructions with $41 \%$ correct responses $\left(\mathrm{t}_{(20)}=0.083\right.$, $\mathrm{P}=0.45$ ), his performance was at chance level. Yet, as with both types of psychological constructions, he had below chance performance with $31 \%$ correct responses $\left(\mathrm{t}_{(20)}=2.00, \mathrm{P}=0.166\right)$ in subject experiencer structures and $22 \%$ correct responses $\left(\mathrm{t}_{(20)}=2.26, \mathrm{P}=0.180\right)$ in object experiencer constructions. As for subject four (GL), again a similar pattern was observed with subjects performing above the chance at both, subject agent with 91 correct responses $\left(\mathrm{t}_{(20)}=3.25, \mathrm{P}=0.0005\right)$ and subject cleft with 86 correct responses $\left(\mathrm{t}_{(20)}=3.18, \mathrm{P}=0.0005\right)$. Although this subject had below the chance performance in object cleft constructions $\left(\mathrm{t}_{(20)}=1.30, \mathrm{P}=0.250\right)$, in agentive passive constructions, his performance was at chance level $\left(\mathrm{t}_{(20)}=0.82, \mathrm{P}=0.45\right)$. However, regarding both types of 
psychological predicate constructions, his performance was significantly below the chance. That is, in subject experiencer constructions, he had $24 \%$ correct responses $\left(\mathrm{t}_{(20)}=-1.46, \mathrm{P}=0.824\right)$ and in object experience constructions, he had just $19 \%$ correct responses $\left(\mathrm{t}_{(20)}=-1.80\right.$, $\mathrm{P}=0.838$ ). In contrast to agrammatic Broca's patients, regarding the control group, one-way repeated measures ANOVA for the sentence types demonstrated no main effect of sentence type $\left(\mathrm{F}_{(6,39)}=0.87, \mathrm{P}=0.43\right)$. They performed very well on all sentence types of subject agentive, agentive passive, object clefts, subject experiencer, and object experiencer types with 98\%, 96\%, 93\%, 94\%, and $90 \%$ correct responses, respectively.

\section{Grammaticality judgment task}

Subject 1 (MS) performed above the chance in all constructions, including subject agent with $96 \%$ correct responses $\left(\mathrm{t}_{(20)}=3.87, \mathrm{P}=0.005\right)$, subject cleft with $92 \%$ correct responses $\left(\mathrm{t}_{(20)}=3.3, \mathrm{P}=0.005\right)$, agentive passives with $88 \%$ correct responses $\left(\mathrm{t}_{(20)}=3.26, \mathrm{P}=0.005\right)$, object clefts with $91 \%$ correct responses $\left(\mathrm{t}_{(20)}=3.26, \mathrm{P}=0.005\right)$, subject experiencer with $84 \%$ correct responses $\left(\mathrm{t}_{(20)}=\right.$ $2.78, \mathrm{P}=0.005$ ), and ultimately, object experiencer with $75 \%$ correct responses $\left(\mathrm{t}_{(20)}=1.817, \mathrm{P}=0.005\right)$. Also, subject two (BR) performed above the chance in all syntactic constructions with $91 \%$ correct responses in subject agentive $\left(\mathrm{t}_{(20)}=3.78, \mathrm{P}=0.005\right), 89 \%$ correct responses in the subject cleft $\left(\mathrm{t}_{(20)}=3.68, \mathrm{P}=0.005\right)$, agentive passives with $85 \%$ correct responses $\left(\mathrm{t}_{(20)}=2.87, \mathrm{P}=0.005\right)$, object clefts with $93 \%$ correct responses $\left(\mathrm{t}_{(20)}=3.27\right)$, subject experiencer with $80 \%$ correct responses $\left(\mathrm{t}_{(20)}=2.71\right.$, $\mathrm{P}=0.005)$, and ultimately, object experiencer with $71 \%$ correct responses $\left(\mathrm{t}_{(20)}=1.808, \mathrm{P}=0.005\right)$.

Subject three (SP) had an intact performance on the subject agent with $98 \%$ correct responses $\left(\mathrm{t}_{(20)}=4.21\right.$, $\mathrm{P}=0.005$ ), subject cleft with $95 \%$ correct responses $\left(\mathrm{t}_{(20)}=3.73, \mathrm{P}=0.005\right)$, agentive passives with $89 \%$ correct responses $\left(\mathrm{t}_{(20)}=2.92, \mathrm{P}=0.005\right)$, object clefts with $85 \%$ correct responses $\left(\mathrm{t}_{(20)}=3.15\right)$, subject experiencer with $88 \%$ correct responses $\left(\mathrm{t}_{(20)}=2.79, \mathrm{P}=0.005\right)$, and ultimately, object experiencer with $71 \%$ correct responses, $\left.\mathrm{t}_{(20)}=1.84, \mathrm{P}=0.005\right)$. Subject four (GL) performed above the chance in subject agent with $92 \%$ correct responses $\left(\mathrm{t}_{(20)}=3.82, \mathrm{P}=0.005\right)$, in subject clefts with $89 \%$ correct responses $\left(\mathrm{t}_{(20)}=3.168, \mathrm{P}=0.005\right)$, in agentive passives with $82 \%$ correct responses $\left(\mathrm{t}_{(20)}=3.166, \mathrm{P}=0.005\right)$, in object cleft constructions with $87 \%$ correct responses $\left(\mathrm{t}_{(20)}=3.22, \mathrm{P}=0.005\right)$, in subject experiencer constructions with $76 \%$ correct responses $\left(\mathrm{t}_{(20)}=1.88, \mathrm{P}=0.005\right)$, and ultimately, in object experiencer constructions with $68 \%$ correct responses $\left(\mathrm{t}_{(20)}=1.79 . \mathrm{P}=0.005\right)$.

\section{Discussion}

As observed, while our patients performed above the chance at both subject agentive and subject cleft constructions, in the syntactic comprehension task, they performed very poorly in some constructions, including agentive passives, object clefts, subject experiencer, and object experiencer constructions. This inconsistency in subjects' performance could be accounted for in different ways:

First, it seems that in pro with the predictions of mapping hypothesis, in constructions where syntactic heuristics is observed, subjects would perform above the chance (Berndt, Mitchum \& Wayland, 1997; Kolk \& Weijts, 1996), explaining their good performance in subject agentive and subject cleft constructions. In other words, these two structures should be regarded as canonical syntactic forms because, in both, the semantic role of the agent was assigned or mapped to the syntactic role of the subject facilitating the subjects' performance. In contrast, in all remaining constructions, including subject experiencer, object experiencer, object cleft, and agentive passive constructions, this canonicity impact was not observed in that the syntactic role of the subject or thematic role hierarchy was violated culminating in subjects' poor performance in syntactic comprehension task. In this respect, our results are in pro with those of other researchers who attributed Broca's aphasics' poor performance in syntactic comprehension tasks to the disruption in the mapping capability of patients. Henceforth, our subjects' performance could be explained well according to the predictions and framework of the mapping hypothesis. For example, in object cleft constructions, the hierarchical syntactic-semantic taxonomy is violated, in which it is the semantic role of the object rather than the subject, which occupies the initial position of the sentence demonstrating the influential role of syntactic heuristics in subjects' interpretations. Also, the semantic role of the theme (patient) took over that of the agent. As mentioned earlier, an important note regarding the unique syntactic structure of Persian is that a pronominal clitic could be attached to the verb bearing the same semantic role. Although this property should have facilitated Broca's patients' performance, surprisingly, it did not have any influence on their comprehensive abilities. However, in agentive passive structures, again the linear concatenation of syntactic roles is disrupted, in which it is the object occupying the initial subject position. Moreover, this time, our noun phrase would bear the semantic role of the theme. Ultimately, psychological constructions violate canonical syntactic structures whether they assign the semantic role of experience to the subject (subject experiencer) or they attribute the semantic role of the experiencer to the 
object (object experiencer). As Pinango (2000) asserted that while these two predicates are psycholinguistically interesting, the latter is more attractive, which plays a less agent-like semantic role (theme) in the subject position. In other words, the more remote semantic category in the canonical semantic hierarchy is promoted to the subject position, the more problems Broca's patients would have comprehended the sentence. Broca's patients' poor comprehension of syntactically complex structures has already been corroborated in both processing (Friederici \& Frazier 1992; Kolk, 1995; Wulfec, 1987; Wulfec, et al, 1991) as well as the representational account of agrammatism (Bradley, et al., 1980; Caplan, et al., 1988; Caramaza \& Zurif, 1976).

In light of this research, it should be highlighted that it is not merely the number of predicates in a sentence that would make it more complex but also the type of predicates (psychological \& agentive) that would play an outstanding role in its complexity. Moreover, subjects' poor performance in the aforementioned structures demonstrates that semantic hierarchy violations and heuristics all by all could be envisaged as potential culprits for subjects' poor performance. Yet, regarding the grammaticality judgment task as reported, all our patients performed above the chance demonstrating their rather intact syntactic abilities. This finding is in line with previous studies, which verified Broca's patients' intact performance in the aforementioned task (Linebarger et al., 1983; Linebarger, 1995; Wulfec et al., 1991) and is not consistent with other studies (Kolk \& Weijts, 1996; Raghibdoust, 1999) emphasizing subjects' poor performance on the task.

The pattern of dissociation in subjects' performancetheir intact performance on the grammaticality judgment task versus their poor performance on the syntactic comprehension task- could be explained within the framework of mapping hypothesis more conveniently. First, it seems that at the first level of syntactic parsing, agrammatic performs very well justifying their intact performance on the grammaticality judgment task; however, it is in the second stage that their semantic representation problems emerge, in which they are incapable of utilizing stored syntactic information to assign thematic roles to the syntactic categories explaining their poor performance on syntactic comprehension task (Linebarger, 1995). Henceforth, agrammatics' difficulty lies in the specifically designated deficit impeding them to assign thematic roles properly to their appropriate positions in the syntactic nodes (Ingram, 2007).

As our ultimate comment, it should be emphasized that in order to detect the possible patterns of syntactic comprehension in agrammatic, more comprehensive studies with a larger sample in diverse languages utilizing diverse tasks and methodologies should be conducted. Moreover, the socio-demographic, as well as psychological characteristics of patients, should also be constrained. By meeting all these variables in various studies, we can more scientifically and systematically underpin the nature of their syntactic knowledge. This dissociation between our subjects' performance on grammaticality judgment and syntactic comprehension tasks has already been attested in diverse studies (Wulfec, 1987; Wulfec et al., 1991). This incongruence between subjects' performance on diverse tasks could be attributed to the recruitment of distinctive processing mechanisms activated at different levels of linguistic processing (Grodzinsky, 1983; Wulfec, 1987).

\section{Conclusion}

Canonicity plays a fundamental role in the syntactic comprehension of aphasic patients. Consequently, as speech therapists, neuropsychologists, and caregivers recruit those structures which are in line with the principles of the mapping hypothesis, they could pave the way for more satisfactory communication of aphasic patients.

\section{Ethical Considerations}

\section{Compliance with ethical guidelines}

All ethical principles were considered in this article. The participants were informed about the purpose of the research and its implementation stages. They were also assured about the confidentiality of their information and were free to leave the study whenever they wished, and if desired, the research results would be available to them. Our research was was approved by the Research Ethics Committee of the University of Gonabad (permission number: 2020/52201/3820/230).

\section{Funding}

This research did not receive any grant from funding agencies in the public, commercial, or non-profit sectors.

\section{Conflict of interest}

The authors declare no conflict of interest.

\section{Acknowledgments}

We would like to express our sincerest thanks to our participants as well as their families for their warm cooperation in the study. 


\section{Reference}

Beretta, A., \& Munn, A. (1998). Double-agents and trace-deletion in agrammatism. Brain and Language, 65(3), 404-421. [DOI:10.1006/brln.1998.1997] [PMID]

Berndt, R. S., Mitchum, C. C., \& Wayland, S. (1997). Patterns of sentence comprehension in aphasia: A consideration of three hypotheses. Brain and Language, 60(2), 197-221. [DOI:10.1006/brln.1997.1799] [PMID]

Bradley, D. C., Garrett, M. F., \& Zurif, E. B. (1980). Syntactic deficits in Broca's aphasia. Biological Studies of Mental Processes, 269-286.

Byng, S. (1988). Sentence processing deficits: Theory and therapy. Cognitive Neuropsychology, 5(6), 629-676. [DOI:10.1080/02643298808253277]

Caplan, D., Hildebrandt, N., \& Marshall, J. C. (1988). Disorders of syntactic comprehension. Massachusetts: MIT Press. [Link]

Caplan, D., Waters, G., DeDe, G., Michaud, J., \& Reddy, A. (2007). A study of syntactic processing in aphasia I: Behavioral (psycholinguistic) aspects. Brain and Language, 101(2), 103-150. [PMID]

Caramazza, A., \& Zurif, E. B. (1976). Dissociation of algorithmic and heuristic processes in language comprehension Evidence from aphasia. Brain and Language, 3(4), 572-582. [DOI:10.1016/0093-934X(76)90048-1] [PMID]

Chomsky, N. (1982). Some concepts and consequences of the theory of government and binding. Massachusetts: MIT Press. [Link]

Chomsky, N. (1993). Lectures on government and binding: The Pisa lecture. Berlin: De Gruyter Mouton. [DOI:10.1515/9783110884166]

Cho-Reyes, S., \& Thompson, C. K. (2012). Verb and sentence production and comprehension in aphasia: Northwestern Assessment of Verbs and Sentences (NAVS). Aphasiology, 26(10), 1250-1277. [PMID] [PMCID]

Dragoy, O., \& Bastiaanse, R. (2010). Verb production and word order in Russian agrammatic speakers. Aphasiology, 24(1), 28-55. [DOI:10.1080/02687030802586902]

Evans, W. S., Hula, W. D., \& Starns, J. J. (2019). Speed-accuracy trade-offs and adaptation deficits in aphasia: Finding the "Sweet Spot" between overly cautious and incautious responding. American Journal of Speech-Language Pathology, 28(1S), 259277. [DOI:10.1044/2018_AJSLP-17-0156] [PMID] [PMCID]

Ferrill, M., Love, T., Walenski, M., \& Shapiro, L. P. (2012). The time-course of lexical activation during sentence comprehension in people with aphasia. American Journal of SpeechLanguage Pathology, 21(2), S179-S189. [DOI:10.1044/10580360(2012/11-0109)] [PMID]

Frazier, L. (1995). Constraint satisfaction as a theory of sentence processing. Journal of Psycholinguistic Research, 24(6), 437-468. [DOI:10.1007/BF02143161] [PMID]

Frazier, L., \& Friederici, A. (1991). On deriving the properties of agrammatic comprehension. Brain and Language, 40(1) 51-66. [DOI:10.1016/0093-934X(91)90116-I] [PMID]
Friederici, A. D., \& Frazier, L. (1992). Thematic analysis in agrammatic comprehension: Syntactic structures and task demands. Brain and Language, 42(1), 1-29. [DOI:10.1016/0093934X(92)90053-H] [PMID]

Garraffa, M., \& Grillo, N. (2008). Canonicity effects as grammatical phenomena. Journal of Neurolinguistics, 21(2), 177197. [DOI:10.1016/j.jneuroling.2007.09.001]

Goodglass, H., \& Kaplan, E. (1972). The assessment of aphasia and related disorders. Philadelphia: Lea \& Febiger. [Link]

Grodzinsky, A. J. (1983). Electromechanical and physicochemical properties of connective tissue. Critical Reviews in Biomedical Engineering, 9(2), 133-199. [PMID]

Grodzinsky, Y. (1995). Trace deletion, theta-roles, and cognitive strategies. Brain and Language, 51(3), 469-497. [DOI:10.1006/brln.1995.1072] [PMID]

Grodzinsky, Y. (2000). The trace deletion hypothesis and the tree-pruning hypothesis: Still valid characterizations of Broca's aphasia. Behavioral and Brain Sciences, 23(1), 55-64. [DOI:10.1017/S0140525X00582399]

Grodzinsky, Y., \& Finkel, L. (1998). The neurology of empty categories: Aphasics' failure to detect ungrammaticality. Journal of Cognitive Neuroscience, 10(2), 281-292. [DOI:10.1162/089892998562708] [PMID]

Grodzinsky, Y., Swinney, D.,\& Shapiro, L. P. (2000). Language and the brain: Representation and processing. Amsterdam: Elsevier Science. [Link]

Haarmann, H. J. (1993). Agrammatic aphasia as a timing deficit. Nijmegen: Nijmegen Institute for Cognition and Information. [Link]

Haarmann, H. J., \& Kolk, H. H. (1991). Syntactic priming in Broca's aphasics: Evidence for slow activation. Aphasiology, 5(3), 247-263. [DOI:10.1080/02687039108248527]

Hickok, G., Zurif, E., \& Canseco-Gonzalez, E. (1993). Structura description of agrammatic comprehension. Brain and Language, 45(3), 371-395. [DOI:10.1006/brln.1993.1051] [PMID]

Ingram, J. C. (2007). Neurolinguistics: An introduction to spoken language processing and its disorders. Cambridge: Cambridge University Press. [DOI:10.1017/CBO9780511618963]

Karimi, S. (2003). On object positions, specificity, and scrambling in Persian. In S. Karimi (Ed.), Word order and scrambling (pp. 91-124). New Jersey: Blackwell Publishing Ltd. [DOI:10.1002/9780470758403]

Karimi, S. (2008). A minimalist approach to scrambling: Evidence from Persian. Walter de Gruyter. [DOI:10.1515/9783110199796]

Kolk, H. (1995). A time-based approach to agrammatic production. Brain and Language, 50(3), 282-303. [DOI:10.1006/ brln.1995.1049] [PMID]

Kolk, H. H., \& Van Grunsven, M. M. (1985). Agrammatism as a variable phenomenon. Cognitive Neuropsychology, 2(4), 347-384. [DOI:10.1080/02643298508252666]

Kolk, H., \& Weijts, M. (1996). Judgments of semantic anomaly in agrammatic patients: Argument movement, syntactic complexity, and the use of heuristics. Brain and Language, 54(1), 86-135. [DOI:10.1006/brln.1996.0062] [PMID] 
Linebarger, M. C. (1995). Agrammatism as evidence about grammar. Brain and Language, 50(1), 52-91. [DOI:10.1006/ brln.1995.1040] [PMID]

Linebarger, M. C., Schwartz, M. F., \& Saffran, E. M. (1983) Sensitivity to grammatical structure in so-called agrammatic aphasics. Cognition, 13(3), 361-392. [DOI:10.1016/00100277(83)90015-X] [PMID]

Mehri, A., Ghorbani, A., Darzi, A., Jalaie, S., \& Ashayeri, H. (2016). Comparing the production of complex sentences in Persian patients with post-stroke aphasia and non-damaged people with normal speaking. Iranian Journal of Neurology, 15(1), 28-33. [PMID]

Meyer, A. M., Mack, J. E., \& Thompson, C. K. (2012). Tracking passive sentence comprehension in agrammatic aphasia. Journal of Neurolinguistics, 25(1), 31-43. [DOI:10.1016/j.jneuroling.2011.08.001] [PMID] [PMCID]

Nilipour, R. (2000). Agrammatic language: Two cases from Persian. Aphasiology, 14(12), 1205-1242. [DOI:10.1080/02687030050205723]

O'Grady, W., \& Lee, M. (2005). A mapping theory of agrammatic comprehension deficits. Brain and Language, 92(1), 91100. [DOI:10.1016/j.bandl.2004.05.009] [PMID]

Omazic, M. (2008). Processing of idioms and idiom modifications: A view from cognitive linguistics. Phraseology: A Interdisciplinary Perspective, 67-79. [DOI:10.1075/z.139.09oma]

Piñango, M. M. (2000). Canonicity in Broca's sentence comprehension: The case of psychological verbs. In Y. Grodzinsky, L. P. Shapiro, \& D. Swinney (Eds.), Language and the brain (pp. 327-350). Massachusetts: Academic Press. [DOI:10.1016/B978-012304260-6/50019-0]

Raghibdoust, S. (1999). Comprehension and grammaticality judgement in Persian-speaking agrammatics. Ottawa: University of Ottawa. [DOI:10.20381/ruor-15937]

Salehnejad, L., \& Shekaramiz, M. (2016). Agrammatism in adult Persian Broca's aphasia: A case study. Journal of Language Teaching and Research, 7(5), 1014-1021. [DOI:10.17507/jltr.0705.24]

Schwartz, M. F., Fink, R. B., \& Saffran, E. M. (1995). The modular treatment of agrammatism. Neuropsychological Rehabilitation, 5(1-2), 93-127. [DOI:10.1080/09602019508520177]

Schwartz, M. F., Linebarger, M. C., \& Saffran, E. M. (1985). The status of the syntactic deficit theory of agrammatism. In M. Louise Kean (Ed.), Agrammatism (pp. 83-124). Massachusetts: Academic Press. [DOI:10.1016/B978-0-12-402830-2.50008-0]

Seidenberg, M. S., \& MacDonald, M. C. (2001). Constraint satisfaction in language acquisition and processing. In $\mathrm{M}$. H. Christiansen \& N. Chater (Eds.), Connectionist psycholinguistics (pp. 281-318). New Jersey: Ablex Publishing. [Link]

Shiani, A., Joghataei, M. T., Ashayeri, H., Kamali, M., Razavi, M. R., \& Yadegari, F. (2019). Comprehension of complex sentences in the Persian-speaking patients with aphasia. Basic and Clinical Neuroscience, 10(3), 199-208. [DOI:10.32598/ bcn.9.10.185] [PMID] [PMCID]

Tesak, J., \& Code, C. (2008). Milestones in the history of aphasia: Theories and protagonists. London: Psychology Press. [DOI:10.4324/9780203934869]
Wassenaar, M., \& Hagoort, P. (2007). Thematic role assignment in patients with Broca's aphasia: Sentence-picture matching electrified. Neuropsychologia, 45(4), 716-740. [DOI:10.1016/j.neuropsychologia.2006.08.016] [PMID]

Wulfeck, B. B. (1987). Sensitivity to grammaticality in agrammatic aphasia: Processing of word order and agreement violations [PhD dissertation]. San Diego: University of California. [Link]

Wulfeck, B., Bates, E., \& Capasso, R. (1991). A crosslinguistic study of grammaticality judgments in Broca's aphasia. Brain and Language, 41(2), 311-336. [DOI:10.1016/0093934X(91)90158-W] [PMID] 
This Page Intentionally Left Blank 